\title{
DEVELOPING AUDIENCES, DEVELOPING LEARNING: AUDIENCE NEEDS AND THE NATURE OF LEARNING
}

\section{Peter Clarke}

Museums are by their nature, cultural institutions. Culture can be seen in many ways, as a commodity, as a social construct or as a political tool.

We make many assumptions about cultural institutions. We develop cultural norms that shape our behaviour, attitudes and opinions. We read cues from our environment as well as from signs and notices. We develop patterns of behaviour to match cultural, social and personal contexts. We adopt multiple behaviours to conform to the many communities we inhabit.

As museum professionals we tend to become blind to the semiotics of our institutions - we loose sight of the underlying concepts we hold of essential functions such as communication, education and audience and loose our ability to modify the behaviour that these concepts generate. If we are to understand how we create 'cultural experience', we need to develop a better understanding of how what we say is derived from these underlying concepts.

There is a degree of interest in the value of culture at this time in the UK.' The Arts have been shown to have significant economic value and the emphasis on the development of educational standards in schools has been extended to lifelong learning. Those institutions that contribute to cultural life at a national and local community level are under pressure to demonstrate their 'value'. We appear to have moved away from the crude value-formoney measures that characterised the market forces political philosophy of previous governments and there now seems to be a genuine attempt to describe value in broader terms and to define the 'additionality' of the outcomes that are created by publicly funded institutions. 


\section{DESCRIPTIVE FRAMEWORKS FOR EDUCATION IN MUSEUMS}

Unfortunately, we do not have cultural ready-reckoners to measure our work, or a structure comparable to the school curriculum to provide a framework for setting objectives. In schools, the pressure to measure outcomes has led to improvements in standards, but at some expense to the breadth of the curriculum and to creative aspects of education. The quest for results has led to an emphasis on the 'basics', defined as literacy and numeracy, and a change in the balance between this and education in the arts.

We need to establish methods to describe and measure value and outcomes in museums without, in the process, losing the special characteristics of learning that museums support. But whatever measure we develop, ultimately, the value of a museum is defined by public perception. In this context, as a consultant advising on the management of museums and as an educator involved in the development of programmes, I am interested in two aspects of the museum product as it is seen by members of the public: ${ }^{2}$

\section{How management processes affect the} development of the product, as represented by the experience of the museum by its audiences ${ }^{3}$.

2. How educational programmes can support the museum's product, its ethos and cultural value.

I consider that the museum product is shaped through a complex series of relationships between:

Its collections, buildings and physical presence together with its institutional concepts of:

- the nature of knowledge;

- how people learn;

- the processes of communication;

- the relationship between the museum and its audiences;

- community and culture.

These elements are closely interrelated. They all derive from fundamental 'world views' (Hein 1997), concepts of the position of museums in society and our role in developing, preserving and transmitting 'culture'4. As an educator, I take the view that education underpins these concepts and provides a structure for them. The network of concepts of communication, attitudes towards audiences, the nature of knowledge and the processes of teaching and learning have a major effect on how a museum shapes its educational function and how it perceives its value to its audiences and to society in general. Often, these concepts are not explicitly defined but exist as a substrata of ideas, beliefs and attitudes that only surface in working practices, policies and other management structures. The manifestation of underlying concepts through the day to day working practices have a profound effect on how visitors experience a museum and how they perceive its institutional values and measure its value to themselves and to society.

As a consultant, I support museums through processes of change. Museums seeking to increase visit numbers and to attract new audiences are often looking for a 'key' to unlock their potential and to become more 'user friendly'. An essential element in this process is to examine 
underlying concepts and reveal their effect on the museum's public image. There is a need to ensure that fundamental concepts are consistent, and based on appropriate models if they are to support a co-ordinated, meaningful and tangible ethos that has transparency and is valued by the museum's existing and potential audiences.

Defining concepts of communication, education/learning is no easy task. There are few comprehensive and consistent models that fit the museum context. Models drawn from psychology, communication studies and other areas can be useful for conceptualising complex functions at an intellectual level - but they tend to be deficient when working at a practical level. They are useful in the academic domain but do not always inform problems inherent in, for example, the design of programmes for new audiences or the development of a new exhibit. Nevertheless, it is essential that some degree of consistency is achieved if development is to be managed efficiently and effectively. It is essential that museums become aware of the concepts that underpin their output - if they fail to do this, they can only manage development in a hit or miss way.

\section{A CULTURAL CURRICULUM?}

We have a National Curriculum that shapes the output of the formal education sector and measures outcomes. Museums have been successful in making an essential contribution to this curriculum.

Museums also have their own agendas and have to respond to many other external demands: they have to meet multiple roles without the structure of a curricu- lum. I believe that one reason for the tendency to identify schools' programmes as a major focus of museum education is that the school curriculum provides a safe framework and an established reference point for forming educational objectives. With the increased emphasis on lifelong learning, we now need to establish how museums can contribute towards learning throughout life and to begin to develop our own 'cultural curriculum', while acknowledging that work with schools is still a mainstay of many museum education programmes.

In addition to a cultural curriculum, we need to develop our ability to design and deliver effective programmes for a range of audiences. There is no underpinning methodology for this aspect of education in museums. Museums and museum educators use an eclectic range of theories and approaches when planning their work and quality is variable. 5 . They draw from school and curriculum led approaches, from their own experience of what works and from ideas borrowed from each other. There is often no real understanding of why certain approaches work and how effectively they help or hinder learning. Often, programmes use an approach that is based, at best, only on a loose 'folk psychology' (Osborne) of learning, or at worst, on a mixture of ingredients drawn indiscriminately from an ill-defined range of sources. This leads to inconsistency and can have an unpredictable effect on the perception of the museum by its audiences. The messages sent by a museum through its educational output have a powerful effect on its image but museums themselves are often completely blind to these messages. 


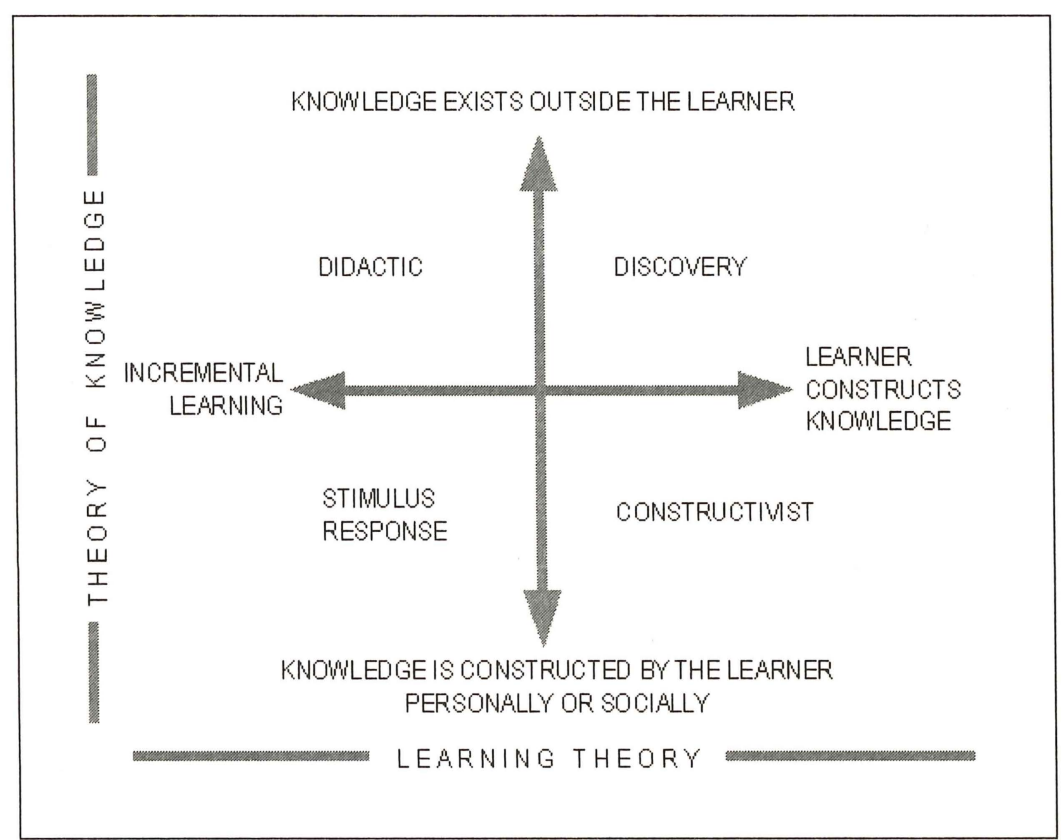

Hein's model, adapted with permission from: Hein (1998 Figure 2.4, p. 25), demonstrates how theories of education are formed from a combination of theories of knowledge and theories of learning.

What follows is an expression of my own ongoing search for practical solutions to complex problems; an attempt to move abstract thinking towards a framework for creating concrete solutions to the everyday problems that museums face and for practical techniques for the analysis of organisational behaviour.

I have used models developed by George Hein as a starting point. Hein works in the area of research and evaluation and his models are intended to illuminate procedures in those domains. They offer one of the best applications of theories drawn from several academic areas to museums. As I shall show later, his models are useful when analysing organisational outputs but they need to be adapted when considering the processes of education in museums. I have rearranged Hein's model to show how it relates to educational method, concepts of learning and communication, and attitudes towards the audience, represented as 'the learner'.

\section{THE HEIN MODEL}

Hein's model (adapted with permission from: Hein 1998 Figure 2.4, p. 25) demonstrates how theories of education are formed from a combination of theories of knowledge and theories of learning. There are two axes representing knowledge and teaching/learning.

The knowledge axis ranges from theories that see knowledge as having an external existence and theories that have knowledge being constructed in the mind. The learning axis ranges from theories that see learning as an incremental process, buil- 
ding step by step, 'filling' an empty vessel, and those theories that see learning as a process of internal construction, as a personal, internal activity or as part of a socially mediated process.

Hein identifies four characteristic outcomes from different combinations of positions on the two axes. The didactic, expository mode; the discovery mode; stimulus-response (behaviourist) mode; and constructivist mode. $\mathrm{He}$ demonstrates how these modes can be related to types of museum and types of museum exhibits. (Hein, 1998)

I do not intend to describe Hein's model in further detail, it is available in his book 'Learning in the Museum', on-line at several sites (ibid) and I have written about it before (Clarke, 1997).

I intend to look at the models of museum education suggested by Hein, but with the addition of other aspects. My objective is to examine exactly how models of education in museums can be related to each other to create an understanding of cultural learning. I will go on to demonstrate how each model draws upon its predecessors and how we need to adopt an inclusive approach to the fixed positions that philosophical theories create.

In this adaptation of Hein's model, I have analysed each mode of instruction to include descriptions of the characteristics of each mode ('educational method') as it is applied in the museum context; the model of teaching and learning that the mode is based on; the model of communication that is associated with the mode; how the learner is conceptualised; and how the process of learning is conceptualised.

\section{THE DIDACTIC MODE}

This position does not require more than a very generalised knowledge of the audience and communication is based on a linear, transmission model. The learner is considered to be the receiver of knowledge based on an accepted canon, usually conforming to an academic model.

The position supports a formal, authoritarian ethos. The audience response is relative to perceptions of the validity and value of the authority represented by the museum. Education is presented by the museum as a 'take it or leave it' offer. If it is not 'taken' the problem is usually considered to rest on the recipient's side of the relationship. They are considered to be not interested, to have varying degrees of stupidity or not worth the effort anyway.

I imagine that many of us can identify

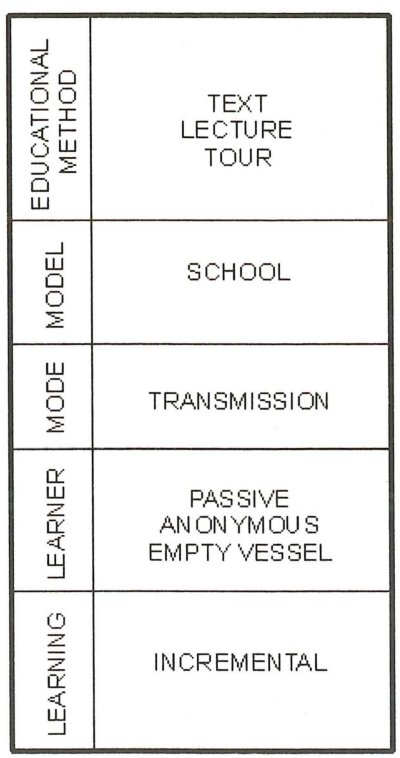

THE DIDACTIC MODE 
106 situations in which certain audiences are considered to be difficult, unrewarding or under-valued. I suggest that the characteristics of the didactic position are partly to blame.

Some research may help to illustrate the results of this mode.

\section{RESEARCH INTO ATTITUDES OF YOUNG PEOPLE TO MUSEUMS}

A small-scale research project has looked at attitudes towards museums amongst school pupils aged 11-16 years (O'Riain, 1997). The research was intended to show how museums could attract this audience for non-school visits.

Visits to museums and galleries came very low on a list of ten leisure-time activities. Going to organised clubs was the only other item that scored consistently lower.

Attitudes towards museums were mixed, but 'boring' was a frequent response. However, on closer investigation, this catch-all term was often modified if activity, 'things to do', personal meaning and freedom to shape their own visit were all available.

There was some evidence to show that attitudes became increasingly negative towards the upper end of the age range.

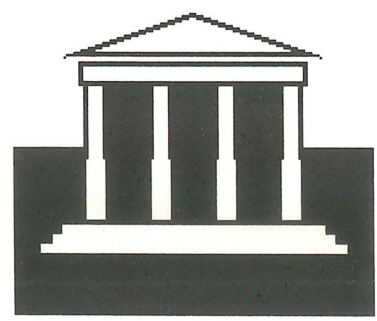

Self-image played an important part in forming perceptions. Pupils felt uncomfortable, out of place, self-conscious and lacking in competence in museums and art galleries.

'Professional smell' - 'interesting, knowledgeable, but boring' - 'everywhere you look, there's things looking at you' - 'when I see real good paintings, it makes me feel jealous' - 'I don't see the point' - 'Art gallery? Don't make me laugh!'

(I have selected these comments to illustrate my point. To be fair, there were positive comments too. However, the report concludes that negative attitudes predominate in this sample, although the respondents did demonstrate an appreciation of the value of museums generally).

A major characteristic of the didactic museum is relevant to these results. The didactic ethos is based on an adult-child relationship. The museum, (representing the adult) decides what the child (represented by the visitor, whatever their age) will learn. There is no need to take account of the audience as individuals or groups of individuals with specific needs, because the transmission mode of communication does not include the need for feedback, and the didactic teaching/learning mode does not give any real significance to previous knowledge. I suspect that this is a factor in the attitudes shown above.

So for the didactic mode, the model of education is the school. The mode of communication is based on transmission. Because the mode is based on the transmission of external knowledge, the learner is not required to be active except to open their empty mind and allow it to be filled. The museum does not need to consider 
the needs of the learner beyond encouraging their attention. Learning proceeds bit by bit controlled by a linear progression through the subject matter which will have been organised in relation to its structural components.

This will result in galleries and exhibits organised around the structure of the relevant domain of knowledge, text as the main vehicle of communication, and objects, pictures etc. tending to illustrate the knowledge embodied in the exhibition. Occasionally, objects (especially art objects) are left to 'speak for themselves'. This could be confused with a purely constructivist position, placing no interference in the way of the observer's personal meaning-making. On the contrary, in the absence of any mediation, no educational method is being employed at all. Some learning may take place as a result of the experience of the object - but that is true of any experience.

The didactic model is the characteristic most commonly expressed by museums. It is important to realise that didactic techniques of 'teaching' are not intrinsically wrong - it is, after all, the mode I am utilising when I deliver this paper as a lecture. The difficulty with the mode occurs when it is used as the major, or only, element underpinning the museum product. Unfortunately, it appears that the concept of 'museum' is closely (perhaps inextricably) associated with a didactic model in the public imagination. Even the icon for 'museum', ubiquitous in the UK, seems to support the authoritarian position that derives from the model of teaching and learning that underpins the didactic museum.

\section{THE DISCOVERY MODE}

The discovery mode will require the use of hands-on interactives, questions and other techniques to support concept formation. The model for discovery learning is 'directed play' but with the aim of transferring fixed knowledge. A defined learning outcome is usually planned by the exhibit's creator and the learner's play activities are usually managed by the 'equipment' and directions provided. There is a correct and incorrect way to engage with the exhibit, usually described in written and pictorial instructions. The 'truth' is often provided in a file of information located nearby.

The designers of discovery exhibits need a generalised knowledge of their audience, often gained through evaluation, which is an important process in the discovery mode to check if objectives are being achieved.

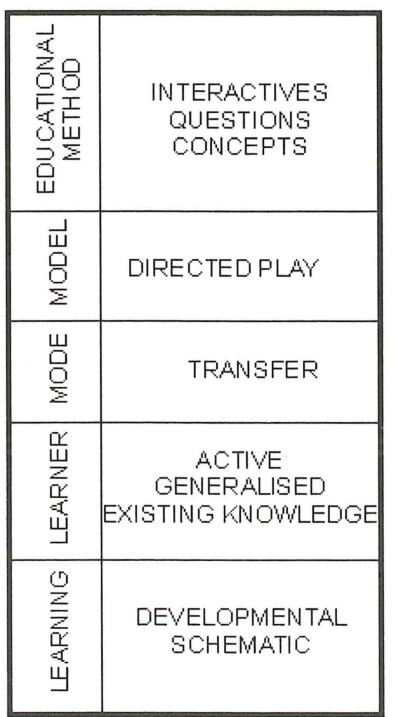

THE DISCOVERY MODE 
108 The language used to describe a discovery exhibit is likely to include references to 'development', 'stages', 'concept formation', 'skills building', 'active learning' 'absorption' etc. The learner's existing knowledge is acknowledged in the discovery mode because it is seen as the basis of development.

Discovery learning sometimes uses techniques borrowed from the stimulus-response quadrant of Hein's model. These behaviourist approaches can produce some bizarre exhibits when combined with discovery learning. The result is often a 'flap' that reveals the 'true' answer and offers a 'reward' - 'That's correct! Well done!' This is an increasingly common approach. We see the technique used in discovery centres, science museums and children's museums.

The key variable in the discovery approach is represented by the question 'what is being discovered?' Hein places his discovery quadrant at the position where knowledge is seen as existing outside the learner - this version of the discovery mode is intended to lead the discoverer (usually imagined as a child) towards the knowledge that forms the objective for the exhibit.

Again, there is nothing intrinsically wrong with this approach as a process except that it often leads to unintended outcomes. Evaluation of discovery exhibits often indicates that the learning resulting from interaction with the exhibit is confused and based on misunderstood ideas. The problem is especially evident in science discovery exhibits that fail to take account of the effect that pre-existing ideas have on the learning outcomes of an exhibit. The major difference between a discovery approach from Hein's upper quadrant and an approach that tends more towards the constructivist quadrant, is how far the learner's starting point is acknowledged and accommodated.

\section{BEHAVIOURIST APPROACHES}

Hein includes this as a discrete quadrant in his model. Behaviourist approaches are based on a stimulus-response-feedbackreinforcement cycle. The approach often translates to lifting a flap to reveal the answer to a question, or multiple choice buttons offering 'rewards' for correct selection, usually presented on a computer screen.

The 'programming' approach to learning in this quadrant is described by Hein with reference to museums that could be considered to be delivering propaganda. However, behaviourist approaches can also exist within the didactic quadrant - after all, the first requirement for creating a behaviourist program, is to analyse knowledge into discrete stages that can be 'taught' in a linear or branching sequence.

\section{CONSTRUCTIVISM}

The key to the constructivist position is the attitude towards the learner. The learner's 'meanings' will be given as much credibility as the 'meanings' of the exhibit design team (the approach probably requires a team effort). Different views and opinions will also be presented in a non-linear, approach that allows many different contextual links to be accommodated.

There will be alternative routes to be taken and the concept of 'redundancy'.

The constructivist approach presents its own problems. Perhaps the most significant is that we do not fully understand 


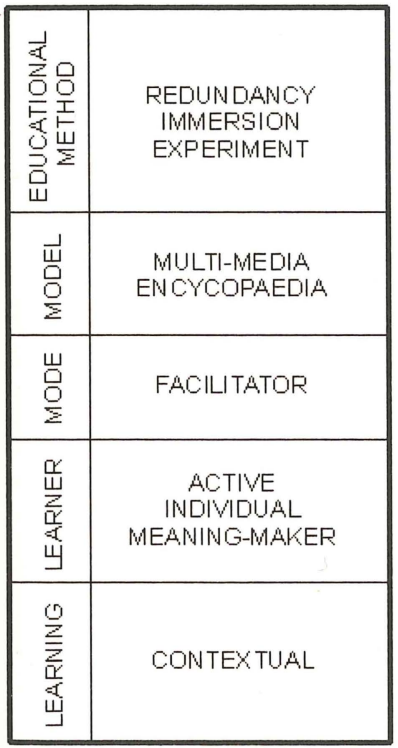

THE CONSTRUCTIVIST MODE

what a constructivist exhibit is like. The characteristics it suggests are: accommodation and recognition of different starting points, non-linear presentation, accommodation of varied learning styles and acceptance of personal meaning-making.

\section{DEVELOPING THE HEIN MODEL}

I have experienced several difficulties when working with Hein's model. These arise not because his model is deficient but because it tends to operate in areas that are very abstract and does not provide me with the practical help that I need. I fully acknowledge that this may be due to differences in the way I have built my own concepts of knowledge and teaching/learning; or to my philosophical naivety (I can only just cope with Sophies World (Gaarder), or to my preferred learning sty- le which is a combination of pragmatic and active approaches. Nevertheless, these doubts perhaps serve to reinforce the need for a working model that is useful in practical situations in museums - because I am certain that I am not alone in wanting to rationalise the process of developing the ability of museums to act as educational institutions.

The first problem is that, although presented as a combination of two continua, the model tends to create fixed positions, stuck in the four quadrants of the model. There is also a tendency to support positions at the extremities of the two axes. Hein has described this tendency as the clash of two deeply held 'world views' that are so deeply formed and create such schisms that they appear irreconcilable ${ }^{4}$.

Although I have presented these modes as a sequence, I believe they need to be seen as a progression where each succeeding mode includes the teaching techniques of its predecessor. So, to create a constructivist exhibition one would need to include didactic and discovery elements in the repertoire. The rationale for this is that, in full acknowledgement of differing learning needs exhibited by individual learners, the constructivist designer will make provision for many modes of learning. However, the overall aim of the exhibition will be to create meaning, not to transmit knowledge.

In reality, I prefer to accept the view that there are different types of knowledge, (or that teaching knowledge and creating meaning are just two different goals), just as there are different modes of learning and different types of learner. This view has been described by Osborne (Osborne, 1996) in a review of the impli- 
110 cations of the constructivist position in science education.

I am also convinced that we need to make use of all available teaching methods if we are to support learning in the complex environment of a museum. Methods based on all four quadrants of Hein's model each have their place when used appropriately.

I am suggesting that we need to use Hein's model as a description of the underlying concepts that create different types of museum product, but that we need to fit our concept of how to deliver learning in the museum into another framework.

\section{CULTURE AS EXCLUSION}

A research project into attitudes of ethnic minorities towards museums and galleries (Desai \& Thomas) confirmed the generic 'museum image' of an old building with grand appearance and a 'quiet reverential atmosphere' (ibid, p 20). Art galleries provoked an elitist image. Many people from ethnic minorities saw museums and galleries as 'white people's territory' and were uncomfortable because they felt conspicuous. They wanted their own cultural backgrounds to be represented.

The research demonstrates how deeply museums are situated in the prevailing culture of their societies - how hegemonic their positions are.

\section{THE SOCIO-LINGUISTIC MODE AND CULTURAL VALUES}

How do we move from cultural exclusivity to an inclusive model of culture?

The socio-linguistic mode ${ }^{7}$ is a develop-

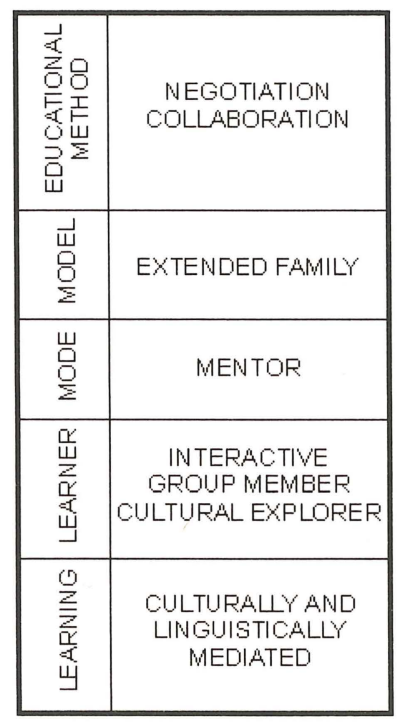

THE SOCIO-LINGUISTIC MODE

ment of the constructivist view. Strictly speaking it has its own roots (Rogoff), but in the museum context it can be regarded as a development of constructivism. Its belief in education as a function of society, mediated by language, is particularly relevant to the development of cultural learning in museums. Essentially it sees learners as part of a social grouping akin to the family. The adult-child relationship is unlike that of the didactic mode because it is concerned primarily with the negotiation of meaning, not the transmission of knowledge. The learner is seen as a cultural explorer with the adult/teacher/mentor in the position of wise co-learner in a co-operative relationship where the boundary between teacher and learner is fluid and reciprocal.

This offers some exciting possibilities for conceptualising learning in museums. In the constructivist mode, the place of 
the teacher begins to be diminished (because the learner makes their own meaning, whatever the teacher does). In the socio-linguistic mode, both learner and teacher, (adult and child) are cast in a partnership of exploration, mediated by language, that results in the creation of values. In a museum context, this translates into a model where a close understanding of audience groups becomes so essential that a real-time relationship is probably required. The museum develops its understanding of audience groups by working directly with them, requiring a planned segmentation and identification of specific communities within the museum's wider audience groupings.

The learning museum will engage in the process of meaning making with a range of communities of learners (Matusov \&
Rogoff), exchanging its traditional role as teacher for a role as co-learner in the development of cultural values. The key to this development is partnership - with audiences, with other educational providers and as part of an organic network of cultural provision.

\section{CONCLUSION}

If we wish to develop attractive and inclusive cultural experiences, we need to develop museums that accommodate multiple views and opinions; allow for alternative cultural perspectives and are fluid in their meaning, without becoming esoteric and inaccessible.

We need to use models of teaching and learning more precisely, utilising the characteristics of each mode in appropriate

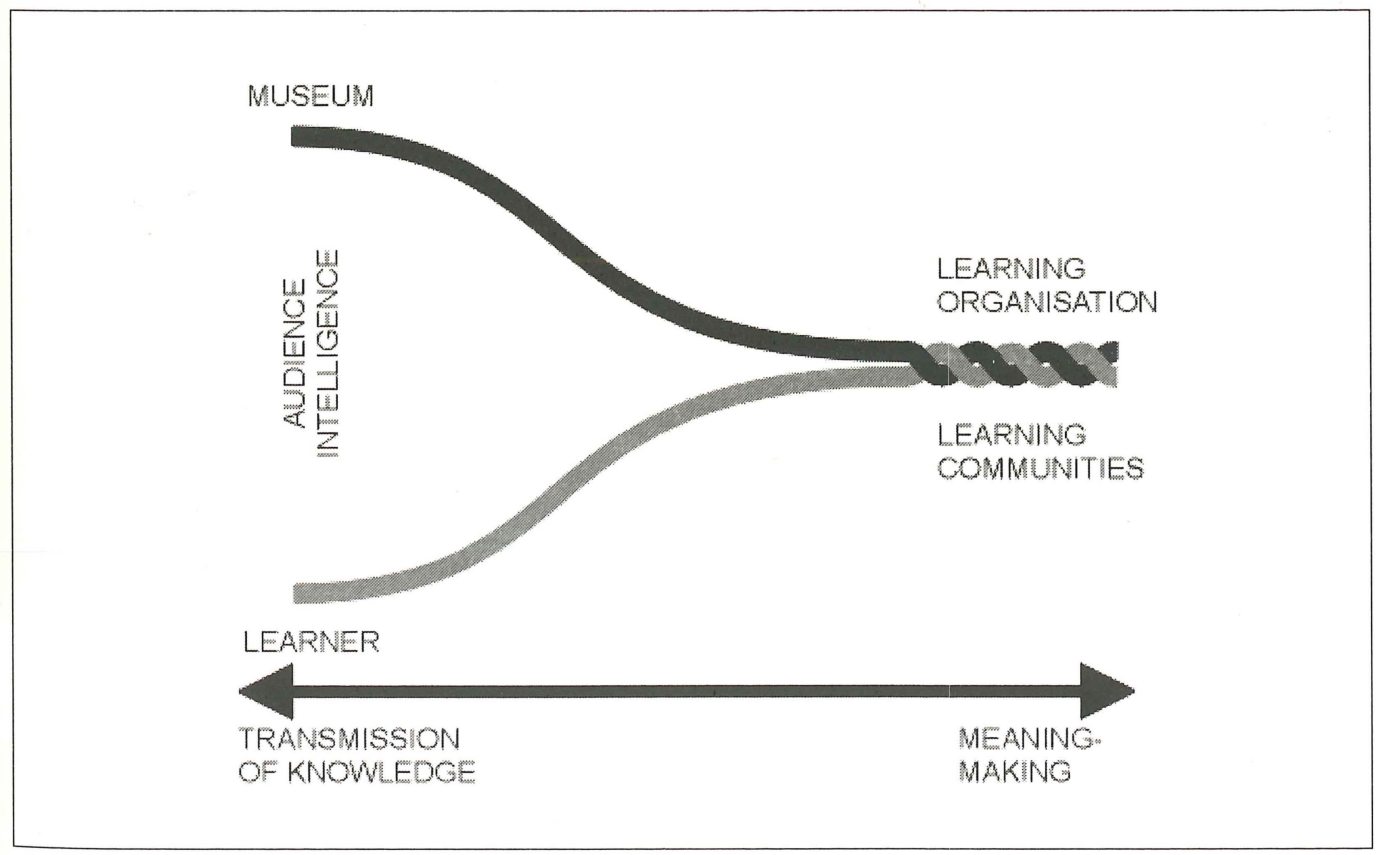


112 ways to match the needs of different learning styles.

We need to see culture as negotiated meaning, belonging to many communities of learners in many forms. Museums and art galleries are where this activity belongs - but they do not own its outcomes.

The key to this process is to be found in a museum's attitude towards its audiences and in a willingness to engage with them as co-learners.

The museum that organises its work around the concept of learning will create an arena in which communities of learners will be free to make their own cultural meanings. The museum will find itself as much in the role of learner as in the role of teacher/instructor/facilitator/mentor and will be able to add meaning to its collections, extend their value and become an active element in the process of cultural development.

\section{NOTES}

1. There are other reasons, at this time in the UK, for developing an ability to understand museums and to be able to demonstrate the effectiveness and quality of our educational work:

A well-argued study for the Association of Independent Museums (AIM), has suggested that with increasing pressure on funding, the need for public accountability and increasing competition within the museum and heritage sector of the leisure market, the level of failure will increase. This will lead either to failure to meet targets and to attract finance for current work and future development, or, in some cases, to terminal failure. (Middleton, 1988)

Following the Anderson report into museum education in the UK (Anderson, 1997), a better understanding of the role museums can play in the provision of greater access to educational opportunities has been developed. The Department of Culture, Media and Sport (DCMS) has recently begun to champion the educational role of museums as part of the Government initiative to extend lifelong learning opportunities to all UK citizens (DfEE, 1998). Funding applications now have to include a strong educational element and demonstrate well-defined community benefits. At the same time, in order to be able to manage and assess the outcomes of the allocation of central and Heritage Lottery Fund grants, DCMS is discussing how performance indicators can sensibly, but effectively, be applied to the educational work of museums.

Also as a response to Anderson (see above), Area Museum Councils have been strongly encouraged to define their own policies for education. Many have created new education posts and, to be able to assess the value of these posts, have begun to seek better benchmarking measures for educational work in their regions. The Museums and Galleries Commission has not yet been able to insist on policies for education as a requirement for its registration scheme, but there is strong pressure for it to do so and the need for well considered education policies has now been clearly established.

2. 'Product' is a term that may be unfamiliar in museum parlance and may be understood in different ways. It includes concepts of value (to all sectors of the audience, see below), output and outcomes. I use it to refer to the overall experience that the museum creates, made up of a complex range of components - services, facilities, personal and institutional communications, exhibits, programmes etc.

3. I use the term 'audiences' to refer to actual and potential visitors, (real or virtual); the interests of 
the museum's trustees, governing body or funding body; and the many communities that exist in and around the museum as a cultural institution. It is similar to the concept of 'stakeholders' but includes ideas more appropriate to organisations that have the attraction of visitors as a major aim.

4. Hein describes two opposing, and apparently irreconcilable positions associated with fundamental concepts, or 'world views' of the nature of knowledge and learning which he calls 'ladder and network theories'. (Hein 1997, Chapter 5).

5. This observation is based on the writer's work as museum consultant on the Museums Economic Growth project which involved 30 museums in the West Midlands Economic Regeneration Region of the UK. The project analysed the products of these museums and established a significant link between museums' attitudes towards audience, education etc and the resulting characteristics of visitors' experiences. A report on the MEG Project is due in 1999 (West Midland Regional Museums Council and Heart of England Tourist Board).

6. Osborne's work is in the area of Science education and defines three realms of knowledge for Science. It is probable that each academic discipline can define its own realms of knowledge. Further investigation into this area and how realms from different areas of knowledge might interrelate in a museum context is the subject of ongoing work. My view that there are different realms of knowledge and that there are corresponding modes of learning, and learners who display preferences for each mode, derive from Osborne.

7. Rogoff describes this mode as 'guided participation'(Rogoff, 1990), or 'transformation of participation' (Rogoff, Matusov and White).

\section{BIBLIOGRAPHY}

Anderson, D. (1997) A Common Wealth: Museums and learning in the $U K$, Department of National Heritage

Bruner, J.S. (1996) The culture of education, Harvard University Press, Cambridge, Massachusetts

Clarke, P. (1997) Developing education in museums, Paper to Foreningen af Danske Kunstmuseer, Esbjerg, 10 September 1997 (http://ds.dial.pipex.com/peterclarke/fdk/mused. html)

Desai, P \& Thomas, A. (1998) Cultural Diversity: Attitudes of Ethnic Minority Populations Towards Museums and Galleries, BMRB International Ltd for Museums and Galleries Commission

DfEE. (1998) The Learning Age: a renaissance for a new Britain, Department for Education and Employment, The Stationery Office, London Gaarder, J Sophie's World, Orion Hein, G.E. (1992) Constructivist learning theory, Developing museum exhibitions for lifelong learning, (ed: Durbin.G) pp30-34 Stationery Office/Group for Education in Museums Hein, G.E. (1998) Learning in the Museum, Routledge.

(An earlier version of the knowledge/learning model is also described on-line at http://www.gem.org.uk/hein.html. Other links to discussions of Hein's paper are given at http://www.gem.org.uk/geminfo.html)

Hooper-Greenhill, E. (1994,a) A new communication model for museums, The educational role of museums, Hooper-Greenhill, E (Ed). Routledge

Hooper-Greenhill, E. (1994,b) 'Museum communication: an introductory essay', The educational role of museums, Hooper-Greenhill, E (Ed). Routledge

Matusov, E and Rogoff, B. (1995) 'Evidence of development from people's participation in communities of learners', in: Public institutions for 
114 personal learning pp 97-104. Editors: Falk, J.

Dierking, L. American Association of Museums

Middleton, V.T.C. (1998) New visions for museums in the 21st Century, Association of Independent Museums, London Transport Museum, London WC2E 7BB

O'Riain, H. (1997) Old objects in glass cases, Harwood, O'Riain and Associates, 9 Bournevale Road, London, SW16 2BA

Osborne, J.F. (1996) Beyond Constructivism, Science Education 80(1): 53-82 John Wiley \& Sons

Rogoff, B. (1990) Apprenticeship in thinking: Cognitive development in social context, Oxford University Press, New York

Rogoff, Matusov and White 'Models of teaching and learning: participation in a community of learners', in Olson, D.R. and Torrance, N (Eds) The handbook of education and human development, (1996) Chapter 18. Blackwell, Cambridge, Massachusetts.

Peter Clarke is a museum consultant working in the areas of education, access and interpretation. He is a visiting lecturer for the Department of Museum Studies, University of Leicester, where he teaches a course for museum educators.

Adr: 15 Hampton Street, Warwick, CV34 6HS, UK Fax +44-(0)1926403489

e-mail:peterclarke@dial.pipex.com 